\title{
The effect of aging on surface roughness of provisional crown and bridge material Zainab Younis Abdullah ${ }^{1 *}$, Suha Fadhil Dulaimi ${ }^{2 *}$
}

\author{
1- Postgraduate student in Prosthetic Dental Technology, Department of Prosthetic Dental \\ Technology, College of Health and Medical Technology, Middle Technical University, Baghdad, \\ Iraq. \\ 2- MSC. Asst. Prof., Department of Prosthetic Dental Technology, College of Health and Medical \\ Technology, Middle Technical University, Baghdad, Iraq. \\ * Corresponding email: suha.f.dulaimi@gmail.com
}

Submit: 2/5/2021 | Accepted: 5/7/2021 | Published: 10/7/2021

\begin{abstract}
Background: Provisional dental restoration fabricated to enhance esthetic, stabilization of abutment teeth and maintain function for limited period of time after which it is to be replaced by definitive fixed restoration. The surface roughness of temporary crowns are considered crucial in achieving successful definite restorations. Most bacteria in the oral cavity can only survive on hard and rough surfaces. The objective of the present study is to evaluate and compare the surface roughness of two types of commercially available composite material (Harvard- temp and Charmtemp). The specimens were tested in dry conditions and after two weeks of storage in artificial saliva at $25^{\circ} \mathrm{C}$. Material and Methods: A total of 32 specimens of dimensions $64 \mathrm{~mm} \times 10 \mathrm{~mm} \times 2.5 \mathrm{~mm}$ were divided in two groups according to the type of material (Harvard-temp or Charm-temp). Each group of material has 16 specimens. These 16 specimens were divided in two groups: a control group (eight specimens) in dry conditions and an aging group (eight specimens) and stored in artificial saliva for two weeks. The TR 200 device was used to measure the surface roughness of specimens in micrometers $(\mu \mathrm{m})$ before and after aging in artificial saliva. Results: After comparing the results, a significant difference was found in the surface roughness in dry and aging conditions of Harvard - temp $(\mathrm{P}<0.05)$. However, there is a non-significant effect noticed for the dry and aging condition of Charm-temp groups $(\mathrm{P}>0.05)$. Conclusion: that in-vitro aging research might be an informative predictor of provisional materials' properties before clinical application.

Clinical significance: Both materials can perform adequately in the oral cavity for two weeks. However, the Charm temp may_perform more adequately and maintain good surface roughness.
\end{abstract}

Keywords: Mechanical Properties, Artificial Saliva, Composite, Surface Roughness, Provisional Restorations.

\section{Introduction}

Temporary prosthesis, this is a fixed and reversible dental / maxillofacial prosthesis intended to improve esthetics, stability, and/or function for a short period before being replaced by a permanent dental or maxillofacial prosthesis; sometimes, such prostheses are used to help in evaluating the therapeutic efficacy of a specific treatment plan or the effectiveness of a specific treatment plan, (1). Giving pulpal health, ensuring positional balance, maintaining occlusal function, and checking functional and esthetic suitability for the patient are only a few of the functions, ${ }^{(2)}$. Provisional products should be selected depending on how well their mechanical, functional, and handling properties satisfy basic criteria in any treatment plan. Biocompatibility and risks from intraoral application, such as chemical damage from monomer residue and heat injury from an exothermic polymerization reaction, are also factors to consider, (3). Provisional Restorations: Description of different types that are used to categorize the items:

1. Fabrication methods (custom made) (Preformed Provisional).

2. The kind of substance that was used (metal) (Resin based).

3. Use period (short-medium-long-term).

4. Fabrication methods (direct-indirect-direct-indirect), ${ }^{(4)}$

Provisional treatment product conditions differ in nature based on the clinical procedures under which the material is required. For example, in anterior esthetic rehabilitation, the esthetic necessity is much more essential than in posterior esthetic rehabilitation. Provisional components used in malocclusion correction and vertical dimension rising cases must also have excellent mechanical properties, ${ }^{(5)}$. Poly methyl-methacrylate and ethyl 
methacrylate resins, polyvinyl-methacrylate resins, compositebased resins, or urethane-based resins are examples of temporary light-curing or auto-polymerizing resin-based materials. New two-component auto-mixing cartridge materials are cutting-edge and have excellent clinical results, ${ }^{(6)}$. Interim materials that are most commonly used they are chemically made up of a combination of two or more forms of material. Composite provisional materials are a wide-ranging group. Bis- acryl resin a hydrophobic agent similar to bis- GMA, is used in the bulk of these materials. Commonly, a variety of multi -

functional resin composite monomer units are used in these products, ${ }^{(4)}$

Bis-acryl resin composite is a temporizing polymer that was introduced in the 1990s to address the drawbacks of poly methyl methacrylate (PMMA) in terms of mechanical, thermal, and device properties. As opposed to the linear structure of poly methyl methacrylate, bis-acryl monomer provides crosslinking with another monomer chain, resulting in strong mechanical properties, (7). Provisional restorations can be identical to definitive restorations in any way except the material used to make them. Provisional restorations are usually made in one of two ways: directly in the mouth or partially on the patient's cast, ${ }^{(8)}$. Surface roughness has an effect on esthetics, color stability, bacterial attachment, and biofilm production. A smooth repair surface should be accomplished to minimize plaque adhesion, gingival irritation, and possible discoloration, ${ }^{(9)}$. The temporary crowned or permanent prosthesis must have a sufficiently smooth surface to be simple, beautiful, and resistant to stains and plaque accumulation. As a result, the required finishing and polishing of dental products are vital components of therapeutic repair procedures, ${ }^{(10)}$. Due to this confusion and the urge to determine and predict the possible reasons for such discrepancy, the aim of the present study is to evaluate and compare the surface roughness of two types of provisional restoration composite material- Harvard temp and Charm temp.

\section{Materials and Method}

Two commercially available provisional crown and bridge materials considered were: composite based temporary materials available as cartridge with dispensing gun and mixing tips: show in (Table 1):

(Table1): Manufacture Composition of materials used in present study

\begin{tabular}{|c|c|c|}
\hline Composites & $\begin{array}{c}\text { Materials } \\
\text { Manufacture }\end{array}$ & Composition \\
\hline $\begin{array}{l}\text { Harvard } \\
\text { temp }\end{array}$ & $\begin{array}{c}\text { ( Harvard } \\
\text { Dental } \\
\text { International } \\
\text { GmbH Mar } \\
\text { garetenstr2-4 } \\
15366 \text { Hoppe } \\
\text { gar ten } \\
\text { Germany }\end{array}$ & $\begin{array}{l}\text { Unsaturated, Esters, } \\
\text { multifunctional meth acrylates, } \\
\text { and, multifunctional acrylates } \\
\text { malonyl urea }\end{array}$ \\
\hline $\begin{array}{l}\text { Charm } \\
\text { temp }\end{array}$ & $\begin{array}{l}\text { Dent Kist, } \\
\text { Inc. Korea }\end{array}$ & Barium Glass, UDMA \\
\hline
\end{tabular}

\section{Samples grouping}

Sample grouping and size calculation

For the Charm-temp two cartridges were used to produce 20 samples. Sixteen samples were selected for study that were free of porosity. However, for the Harvard-temp two cartridges were used to produce 18 samples. Sixteen samples were selected for study that were free of porosity.

A total of 32 specimens were prepared and marked with a specific number describing the type of material and the order of their fabrication. All specimens were measured for accurate dimensions $(64 \mathrm{~mm} \times 10 \mathrm{~mm} \times 2.5 \mathrm{~mm})$ by using venire caliper. The 32 specimens were divided in two groups according to the type of material (Harvard-temp, Charm-temp).

Each group of material had 16 sample specimens which were divided into two group

1- Group A (control): dry conditions - eight specimens

2- Group B (aging): two weeks aging in artificial saliva - eight specimens. A custom metal mold was fabricated for making specimens. This it is a rectangular mold with five slots of dimensions- $64 \mathrm{~mm} \times 10 \mathrm{~mm} \times 2.5 \mathrm{~mm}$. Its open on one side with metal cover and adjustable screws on each ends to carefully remove the specimens

Petroleum Jelly was applied on the inner surface of the mold with the help of a brush. For the composites, the material was dispensed into the slots directly using a dispensing gun The mixing tip of the cartridge was held at one end of the mold and material was expressed into the mold moving the auto mix dispenser slowly to the other end to avoid incorporation of air bubbles while dispensing the material in the mold and covered in metal. A $10 \mathrm{~kg}$ weight was applied as a load to extrude any excess material and to provide smooth surfaces. The material was allowed to set. Once the material was set, the adjustment screws were loosened. Specimens were removed from the mold and excess material trimmed, ${ }^{(11)}$. Show in Fig. 1,2

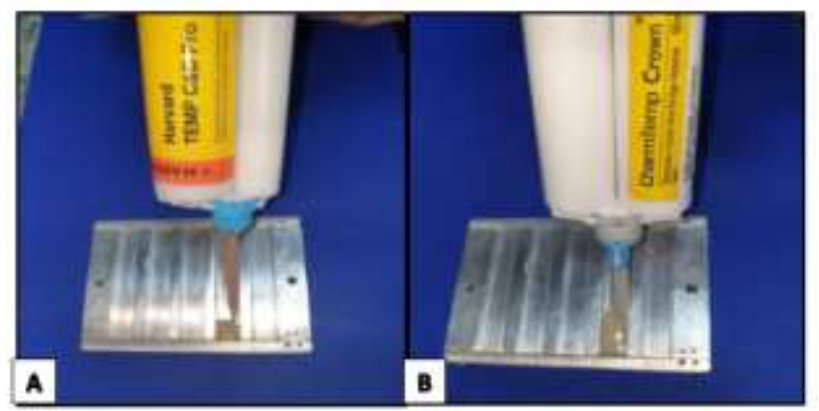

Fig 1 Specimens mold design, material dispensed into slot A, Harvard-temp. B, Charm-temp

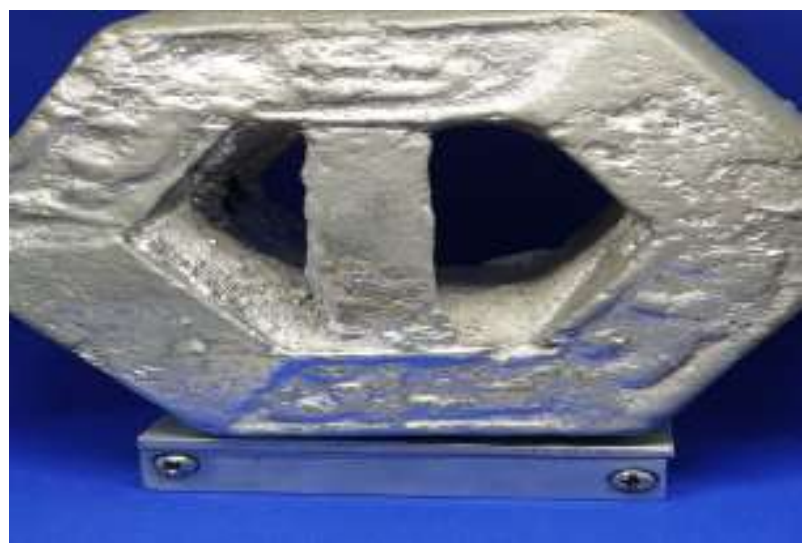

Fig 2 A $10 \mathrm{~kg}$ weight of on the mold 


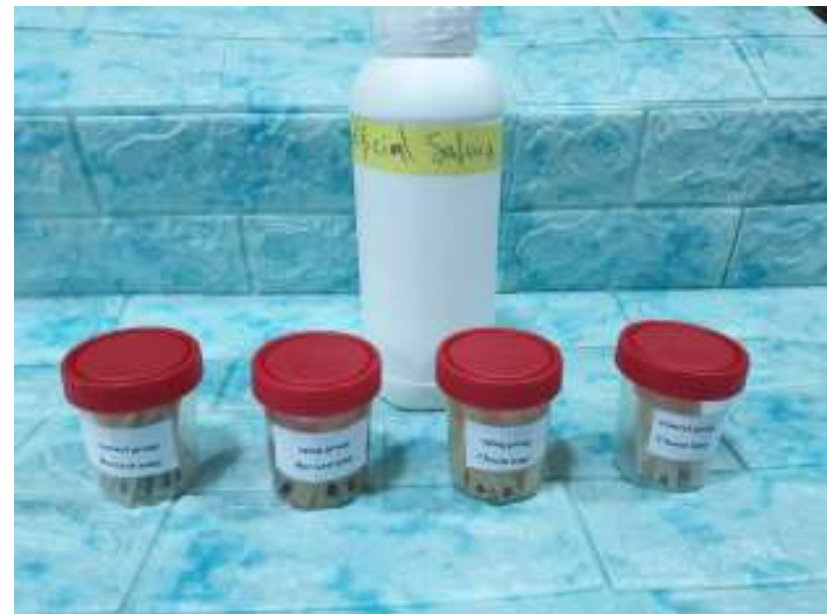

Fig 3 Specimens of Harvard-temp and Charm-temp control and aging groups

\section{Preparation of the artificial saliva}

For the neutral solution (PH 7.0) artificial saliva of the following composition was prepared: 100mL Na2HPO4 $(2.4 \mathrm{~m} \mathrm{M}), 100 \mathrm{~mL}$ of KH2PO4 $(2.5 \mathrm{mM}), 100 \mathrm{~mL}$ of $\mathrm{Na} \mathrm{cl}(1.0 \mathrm{mM}), 100 \mathrm{~mL}$ of $\mathrm{KHCO} 3(1.50 \mathrm{mM}), 100 \mathrm{~mL}$ of $\mathrm{CaCl} 2(1.5 \mathrm{mM}), 100 \mathrm{~mL}$ of $\mathrm{MgCl} 2$ $(0.15 \mathrm{mM})$, and $6 \mathrm{~mL}$ of citric acid $(0.002 \mathrm{mM}),{ }^{(12)}$. Show in Fig. 3

\section{Testing Procedure}

The study specimens were examined by the profile meter surface roughness device surface roughness tester (TR 200, China) Show in Fig. 4 The specimen surface was fixed in a very flat position to the horizontal base of the profile meter by glue, and the stylus (profile meter`s needle) was moved across the surface of each specimen twice in two different directions according to apparatus design. The data were collected from the screen part of the profile meter in micrometers $(\mu \mathrm{m})$ which was subjected to statistical analysis, ${ }^{(13)}$

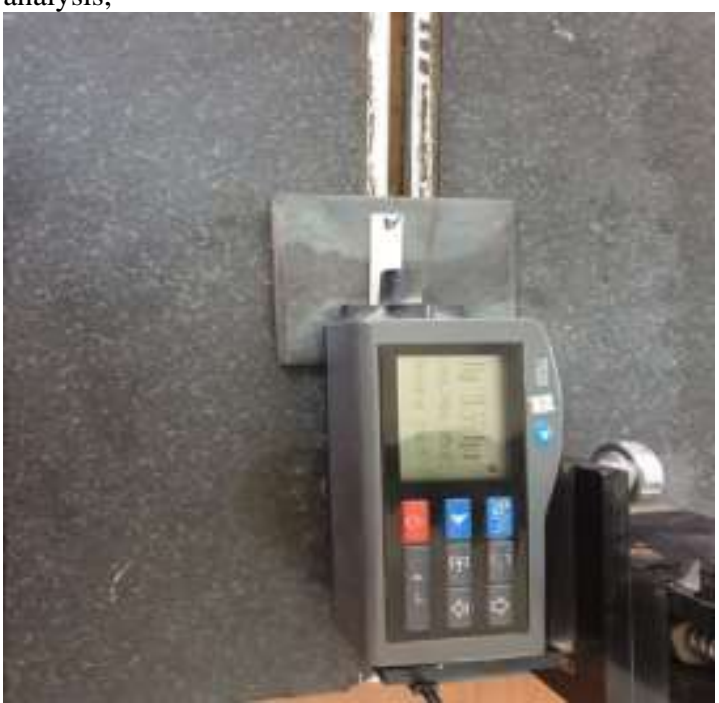

Fig 4 Surface Roughness Tester (TR 200)

\section{Statistical Methods}

IBM SPSS statistical program Version 24 used for doing the statistical analysis of the current study and Microsoft Excel 2010 was used for graphics presentation. The usual statistical methods were used in order to assess and analyze the results; these include Descriptive statistics (mean, standard deviation, minimum, maximum) and Inferential statistics (Student test (t-test).

\section{Results and Discussion}

Descriptive statistics of surface roughness were obtained which include the minimum, maximum, mean and standard deviation for Harvard-temp and Charm-temp of the two groups - dry and aging - in artificial saliva. Fig. 5 shows the highest mean value observed in the Harvard-temp groups.

Comparison between the two groups - dry and aging - in artificial saliva of Harvard- temp using Paired t-test for the surface roughness showed a statistically significant $\mathrm{P}$-value $\mathrm{P}<0.05$ - see Table (2).

Comparison between the two groups - dry and aging - in artificial saliva of Charm -temp using Paired t-test for the surface roughness showed no significant difference in $\mathrm{P}$-value $\mathrm{P}>0.05-$ see Table (2).

Comparison between the Harvard-temp and the Charm-temp for the surface roughness revealed non-significant $\mathrm{P}>0.05$ in dry and aging in artificial saliva - see Table (3).

(Table 2): Paired t-test between dry and aging in artificial saliva of Haravd-temp and Charm-temp

\begin{tabular}{|c|c|c|c|}
\hline Groups & & & \\
\hline $\begin{array}{c}\text { Harvard-temp } \\
\text { Dry vs. Aging }\end{array}$ & 3.625 & .008 & $\mathrm{~S}$ \\
\hline $\begin{array}{c}\text { Charm- temp } \\
\text { Dry vs. Aging }\end{array}$ & 0.342 & .742 & $\mathrm{NS}$ \\
\hline
\end{tabular}


(Table 3): Paired t-test between Harvad-temp and Charm-temp of each experimental groups

\begin{tabular}{|l|c|r|r|l|}
\hline \multicolumn{1}{|c|}{ Groups } & $\begin{array}{c}\text { Harvard } \\
\text { temp } \\
\text { Vs } \\
\text { Charm } \\
\text { temp }\end{array}$ & $\mathrm{t}$ & P-value & Sig \\
\hline $\begin{array}{l}\text { Surface } \\
\text { Roughness }\end{array}$ & Dry & 0.963 & .368 & $\mathrm{NS}$ \\
\cline { 2 - 6 } & aging & 2.052 & .079 & $\mathrm{NS}$ \\
\hline
\end{tabular}

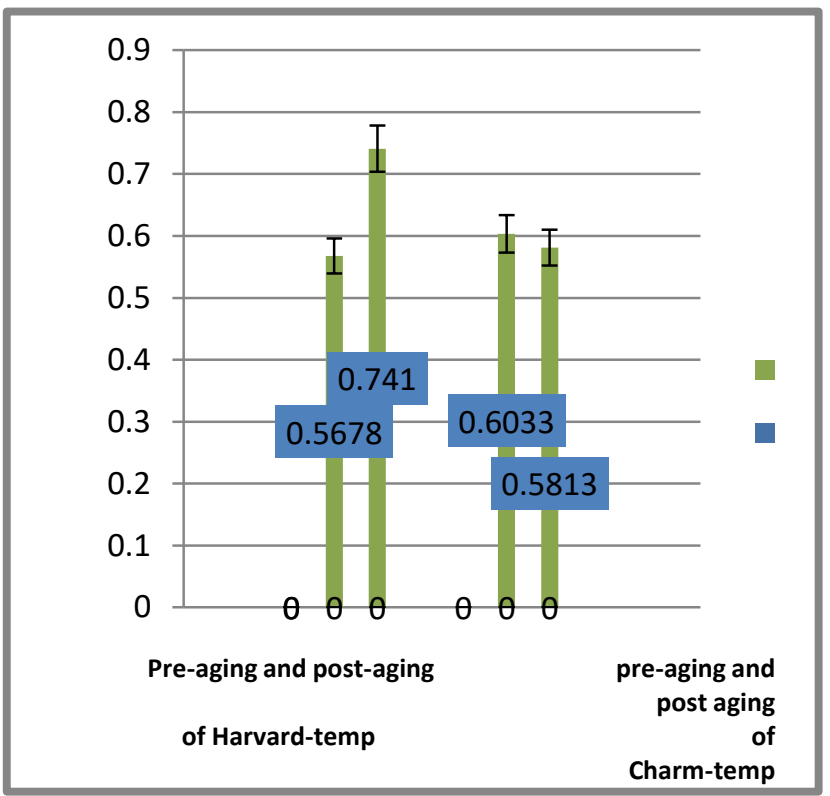

Fig 5 Bar chart showing means of the Surface Roughness in micrometer $(\mu \mathrm{m})$ with standard deviation

\section{DISCUSSION}

Provisional restorations are necessary to preserve prepared teeth, minimize dentinal sensitivity, avoid tooth migration caused by occlusal changes, and restore function, ${ }^{(14)}$. For a sufficient period of time, the provisional reconstruction should be able to tolerate oral pressures such as rapid temperature changes, saturated humidity, and frequent occlusal force, ${ }^{(15)}$ The temporary material selected has traditionally been thermoplastic acrylic [Poly and MMA] products, which have fulfilled many mechanical and physical conditions to some extent. They do, though, have disadvantages. Because of their improved mechanical properties and lower exothermic release ability, the newest composite temporization materials are becoming more common, ${ }^{(16)}$. An ideal provisional restoration material has not yet been developed, (4). Dental restoration should be smooth enough to prevent dental plaque accumulation and consequently periodontal disease, (17) In addition, a rough surface of provisional restoration could become stained more rapidly than a smooth surface would due to surface irregularities which retain stain and plaque, ${ }^{(18)}$ When provisional restorations are required for longer periods of time gingival inflammation and deterioration of esthetic appearance may result, ${ }^{(19)}$. The available materials differ in their surface roughness and their reaction to oral environment, ${ }^{(20)}$ The results of the present study revealed that aging of Harvard-temp in artificial saliva significantly increased the surface roughness $\mathrm{P}$ value $<0.05$. The causative factor for that result is that the Harvard-temp is composite based on multifunctional meth acrylic esters that undergo chemical hydrolysis during aging in saliva and water, ${ }^{(21)}$. However, the Charm-temp was not affected by two weeks aging in artificial saliva: $\mathrm{P}$ - value $>0.05$. The scientific explanation for this result related to the composition of the Charm-temp. Its composite material is based on UDMA monomer and Barium glass fillers. UDMA polymers are characterized by high cross-linking that improves the physical and mechanical properties of composite polymer, ${ }^{(22)}$. In addition, Barium glass inorganic fillers enhanced the physical properties of final composite, ${ }^{(21)}$. However, comparison between the two types studied -provisional restorative material in dry condition and aging in artificial saliva environment- showed no significant difference: P- value $>0.05$. According to, ${ }^{(19)}$ The effect of the type of storage solution on change in surface roughness differed with the particular material, Surface roughness increased for the majority of materials after storage in a moist environment.

There is no universal matrix that produces the smoothest surface: this depends on the compatibility between the resin and the matrix, ${ }^{(23)}$.

\section{Conclusion}

Within the limitation of the present study the following conclusion can be drawn:

1- Provisional crown and bridge material behaved differently after two weeks aging in artificial saliva.

2- Harvard-temp showed significant increased surface roughness after two weeks aging in artificial saliva.

3- Charm - temp surface roughness was not affected by two weeks aging in artificial saliva.

4- No significant difference was found between the two materials when comparing materials in dry conditions and after two weeks aging in artificial saliva.

Clinical significance: Both material can perform adequately in the oral cavity within two weeks. However, Charm -temp may performance adequately maintain good surface roughness.

\section{REFERENCES}

1. S. M. Morgano, C. W. VanBlarcom, K. J. Ferro, and D. W. Bartlett, "The history of The Glossary of Prosthodontic Terms," Journal of Prosthetic Dentistry, vol. 119, no. 3, pp. 311-312, 2018.

2. R. Albahri, H.-I. Yoon, J. D. Lee, S. Yoon, and S. J. Lee, "Shear bond strength of provisional repair materials bonded to 3D printed resin," Journal of Dental Sciences, vol. 16, no.1, pp. 261-267, 2021.

3. P. E. Guru and V. Sengottaiyan, "Awareness among Dental students on different Techniques available for Temporisation in FPD-A Survey," Research Journal of Science and Technology, vol. 11, no.2, pp . 129134, 2019.

4. P. Garg, R. Ravi, and P. Ghalaut, "Outcome of Provisional Restorations on Basis of Materials and Techniques of Choice: A Systematic Review," Restoration, vol.3, no.1, pp.6-15, 2021. 
5. A. El-Beialy, "The effect of type of material and method of construction on the fracture toughness of different commercially available provisional restoration resins," Egyptian Dental Journal, vol. 65, no.4, pp. 3677-3685, 2019.

6. T. Sari, A. Usumez, T. Strasser, A. Şahinbas, and M. Rosentritt, "Temporary materials: comparison of in vivo and in vitro performance," Clinical Oral Investigations, vol. 24, no.11, pp. 4061-4068, 2020.

7. S. Lenglerdphol, "The Effects of surface coating agents on surface micro hardness of bis-acryl provisional materials," Mahidol Dental Journal, vol. 39, no.3, pp. 165-172, 2019.

8. M. Choudhary and V. Singh, "Effect of Cooling Techniques on Pulpal Temperature on Direct Fabrication of Provisional Restorations: An In Vitro Study," International Journal of Research \& Review, vol. 6, no.12, pp. 86-91, 2019.

9. D. Singh, S. M. Ram, N. Shah, and J. Nadgere, " A Comparative Evaluation of Temperature changes, surface roughness and colour stability of three chemically cured composite resin crown and bridge materials for direct provisional restoration-an in vitro study," National Journal of Medical and Dental Research, vol.6, no.4, pp.543-551, 2018.

10. N. U. Lara-Jara, G. F. Romo-Ramírez, M. del Pilar Goldaracena-Azuara, A. Aragón-Piñ, C. B.-T. Girón, M. V. Méndez-González, et al., "Effect of Polishing Procedure on the Roughness and Bacterial Adhesion of Provisional Restorative Materials," Microscopy Research, vol. 6, no.2, pp. 9-18, 2018.

11. A. Singh and S. Garg, "Comparative evaluation of flexural strength of provisional crown and bridge materials-an in vitro study," Journal of Clinical And Diagnostic Research: JCDR, vol. 10, no.8, pp. ZC72, 2016.

12. M. M. Pinto, P. F. Cesar, V. Rosa, and H. N. Yoshimura, "Influence of $\mathrm{pH}$ on slow crack growth of dental porcelains," Dental Materials, vol. 24, no.6, pp. 814-823, 2008.

13. A. Shihab Ahmad, " Evaluation and Compare between the surface roughness of acrylic resin Polished by, white sand and black," Journal Of Kerbala University, vol. 6, no.3, pp. 49-54, 2010.

14. P. D. Ronauk Singh, Poonam Prakash, Vijaya Kumar $\mathrm{R}$, S K Bhandari, "Comparative Evaluation of Various Cooling Techniques on Intra pulpal Temperature Rise during Direct Provisionalization An Ex-vivo Study," International Journal of Contemporary Medical Research, vol. 6, no. 10, pp J4-J9, 2019.

15. T. Reeponmaha, O. Angwaravong, and $T$. Angwarawong, "Comparison of fracture strength after thermo-mechanical aging between provisional crowns made with CAD/CAM and conventional method," The Journal of Advanced Prosthodontics, vol. 12, p. 218-224, no.4, 2020.
16. R. D. Ahmed Ayub Patel, Pallavi Madanshetty , Aamir Zahid Godil , Arshi Ilyas Kazi , Ajinkya Sanjiv Kirad, "Evaluation of Marginal Fit of Three Different Interim Restoration Materials - An In-vitro Study," J Dent Mater Tech, vol. 9, no.3, pp. 161-170, 2020.

17. B. A. Kaplan, G. R. Goldstein, T. Vijayaraghavan, and I. K. Nelson, "The effect of three polishing systems on the surface roughness of four hybrid composites: a profilometric and scanning electron microscopy study," The Journal of Prosthetic Dentistry, vol. 76, no.1, pp. 34-38, 1996.

18. O. Alghamdi, A. Alebdi, and H. Sherfudhin, "Color Stability Evaluation of Different Provisional Materials Immersed in Beverages," The Egyptian Journal of Hospital Medicine, vol. 69, no.5, pp. 25252532, 2017.

19. D. A. M. D.-A. Debra R. Haselton, DDS, MS;2 and P. and Deborah V. Dawson, "Effect of Storage Solution on Surface Roughness of Provisional Crown and Fixed Partial Denture Materials," Journal of Prosthodontics, vol. 13, no.4, pp. 227-232, 2004.

20. D. Şen, G. Göller, and H. İşsever, "The effect of two polishing pastes on the surface roughness of bis-acryl composite and methacrylate-based resins," The Journal of Prosthetic Dentistry, vol. 88, no.5, pp. 527532, 2002.

21. A. Szczesio-Wlodarczyk, J. Sokolowski, J. Kleczewska, and K. Bociong, "Ageing of dental composites based on methacrylate resins-A Critical Review Of The Causes And Method Of Assessment," Polymers, vol. 12, no.4, pp.2-18, 2020.

22. C. J. Floyd and S. H. Dickens, "Network structure of Bis-GMA-and UDMA-based resin systems," Dental Materials, vol. 22, no.12, pp. 1143-1149, 2006.

23. R. Ayuso-Montero, J. Martinez-Gomis, M. LujanCliment, J. Salsench, and M. Peraire, "Influence of matrix type on surface roughness of three resins for provisional crowns and fixed partial dentures," Journal of Prosthodontics: Implant, Esthetic and Reconstructive Dentistry, vol. 18, no.2, pp. 141-144, 2009 